\title{
Facilitated binding of GAL4 and heat shock factor to nucleosomal templates: differential function of DNA- binding domains
}

\author{
Ian C.A. Taylor, Jerry L. Workman, Thomas J. Schuetz, and Robert E. Kingston ${ }^{1}$ \\ Department of Molecular Biology, Massachusetts General Hospital, Boston, Massachusetts 02114 USA; Department of \\ Genetics, Harvard Medical School, Boston, Massachusetts 02115 USA
}

\begin{abstract}
Regulatory factors must contend with chromatin structure to function. Although nucleosome structure and position on promoters can be important in determining factor access, the intrinsic ability of factors to bind to nucleosomal DNA might also play an essential regulatory role. We have used templates where nucleosomes were either randomly positioned or rotationally phased to demonstrate that two transcription factors, heat shock factor (HSF) and GAL4, differ significantly in their ability to bind to nucleosomes. GAL4 was able to bind to nucleosomal templates. Surprisingly, in contrast to its behavior on naked DNA, GAL4 bound better to multiple GAL4 sites than to a single GAL4 site on these templates. HSF alone was not able to bind to nucleosomal templates. HSF was able to bind to nucleosomal templates, however, when the TATA-binding factor TFIID was present. Consequently, binding to nucleosomal templates could be facilitated by adjacent binding of the same protein in the case of GAL4 but required binding of a second protein in the case of HSF. Taken together, these data demonstrate that regulatory factors differ in their inherent ability to bind to nucleosomal templates. These differences are likely to be important to the function of these factors in vivo.
\end{abstract}

[Key Words: Heat shock factor; GAL4; TFIID; nucleosome binding; transcriptional regulation]

Received March 4, 1991; revised version accepted April 12, 1991.

Genomic DNA is compacted into chromatin, the basic unit of which is the nucleosome. Genetic and biochemical studies have revealed that nucleosomes can repress transcription initiation, presumably by inhibiting the formation of an initiation complex by basal factors at the TATA-cap site and by interfering with the ability of regulatory factors to bind to specific sequences (Knezetic and Luse 1986; Lorch et al. 1987; Clark-Adams et al. 1988; Han and Grunstein 1988; for review, see Elgin 1990; Wolffe 1990). For regulated transcription to occur, this repression must be overcome by both the basal and regulatory transcription factors. This raises the question as to how these proteins recognize specific sequences when those sequences are located in a nucleosome.

Several mechanisms that allow access of proteins to chromatin have been proposed (for review, see Svaren and Chalkley 1990; Wolffe 1990). Most of these involve alteration of the nucleosomal array. For example, on the PHO5 and mouse mammary tumor virus (MMTV) promoters, the precise positioning of nucleosomes is thought to ensure access by placing a required site in a nucleosome-free linker region or by aligning a required site such that it is on the side of the DNA duplex di-

\footnotetext{
${ }^{1}$ Corresponding author.
}

rected away from the surface of a nucleosome (Almer and Horz 1986; Richard-Foy and Hager 1987; Perlmann and Wrange 1988; Pina et al. 1990; Archer et al. 1991). Binding of regulatory factors to such sites has been hypothesized to alter nucleosomal structure in a manner that allows other factors to bind (Almer et al. 1986; Cordingley et al. 1987; Pina et al. 1990). Another model suggests that the process of DNA replication might disorganize chromatin structure temporarily as nucleosomes associate with either newly synthesized daughter strand. Thus, transcription factors might have relatively free access to the DNA immediately after replication (Brown 1984; Wolffe and Brown 1988). Binding of some factors to their recognition sequences might then physically exclude the reformation of nucleosomes over those regions and thereby maintain accessibility to additional factors. A phenomenon that these mechanisms must explain is the ability of inducible regulatory factors to bind rapidly to their sites at times other than immediately after replication.

Heat shock promoters, for example, must be available for immediate induction when a cell is stressed. Footprinting studies of Drosophila and human $h s p 70$ genes in intact nuclei have shown that in the absence of stress the promoter regions are accessible to nucleases (hypersen- 
sitive; Wu 1980; Brown et al. 1988; Abravaya et al. 1991). This hypersensitivity is interpreted as being the result of an absence of nucleosomes (for review, see Elgin 1988; Gross and Garrard 1988). Footprinting studies have demonstrated that factors are constitutively bound to the TATA region of both the human and Drosophila $h s p 70$ promoters in vivo (Wu 1984; Abravaya et al. 1991). This suggests a possible involvement of these factors in creating an accessible, nucleosome-free region that allows rapid binding and transcriptional stimulation by the heat shock factor (HSF) upon induction.

A second example of rapid transcriptional induction is the activation of the yeast GAL1-GAL10 genes by the transcription factor GAL4. GAL4 binds as a dimer to the upstream activating sequence $\left(\mathrm{UAS}_{\mathrm{G}}\right)$ situated between the divergent GAL1-GAL10 promoters and stimulates transcription up to 1000 -fold after galactose addition (Hopper et al. 1978; St. John and Davis 1981; West et al. 1984; Giniger et al. 1985; Carey et al. 1989 and references therein). The region of the dual promoter containing $\mathrm{UAS}_{\mathrm{G}}$ is free of nucleosomes, which are thought to be physically excluded by the yeast protein GRF2 which, in turn, also binds to $\mathrm{UAS}_{\mathrm{G}}$ as well as to many other UAS regions (Lohr and Hopper 1985; Fedor et al. 1988; Chasman et al. 1990). In several situations, however, GRF2 binding is not required for GAL4 action (Webster et al. 1988; Fedor and Kornberg 1989; Chasman et al. 1990 |, thus raising the question as to whether the ability of GRF2 to create a nuclease hypersensitive region at $\mathrm{UAS}_{\mathrm{G}}$ is necessary for $\mathrm{UAS}_{\mathrm{G}}$ function.

Although it is clear, therefore, that regulatory factors, such as HSF and GAL4, must bind rapidly to their recognition sequences in chromatin, it is not clear what role the factors themselves play in gaining access to nucleosomal DNA. Previous studies on this issue have focused largely on nucleosomal structure, arguing that either appropriate phasing of nucleosomes on a particular side of the helix or disruption of nucleosomal structure allows factors to interact with their binding sites. The theory we test here is that regulatory factors themselves might have dramatically differing abilities to bind to their recognition sequence on nucleosomal templates. These differences might allow certain factors to gain access to their sites on chromatin containing intact nucleosomes, whereas other factors might require prior alteration of the nucleosomal structure.

We have used purified transcription factors and an in vitro nucleosome assembly system to determine the effect that nucleosomes have on HSF and GAL4 binding. We show that GAL4 and human HSF have contrasting abilities to interact with their recognition site in a nucleosome. HSF demonstrated no ability to bind, whereas GAL4 bound quite readily. In addition, different mechanisms are used to facilitate binding of these factors to nucleosomal templates. Although the GAL4 protein is inherently able to bind to its site in a nucleosome, that binding is facilitated by the presence of multiple GAL4binding sites on the nucleosomal template. In contrast, HSF requires prior binding of a second factor (in our experiments, TFIID) to create access to the heat shock el- ement. These data provide insight into the mechanisms that these and other factors use to function in chromatin and suggest an important regulatory activity for the different DNA-binding motifs employed by sequence-specific upstream transcription factors.

\section{Results}

In this study we use an in vitro system to assemble a variety of DNA fragments containing binding sites for yeast GAL4 and human HSF into nucleosomes. This in vitro system employs a supernatant from heat-treated Xenopus egg extracts as a source of nucleosome assembly factors (primarily nucleoplasmin). The Xenopus supernatants are supplemented with purified histones to generate a reconstituted system that will assemble exogenous DNA into nucleosomes during a 60-min incubation at $30^{\circ} \mathrm{C}$ (Laskey et al. 1978; Workman et al. 1991). In control reactions, histones are omitted to demonstrate that they are required for the observed effects.

Nucleosome core particles assembled in this reconstituted system resemble those from cellular chromatin (Rhodes and Laskey 1989). These reconstituted core particles sediment at $11 \mathrm{~S}$ on sucrose gradients/data not shown) and demonstrate a micrococcal nuclease limit digestion product of $145 \mathrm{bp}$ (Workman et al. 1990). Furthermore, when DNA fragments containing artificial nucleosome positioning sequences are assembled into nucleosome core particles in this reconstituted system, a 10 -base repeating hydroxy-radical cleavage pattern is seen that is indistinguishable from that observed with salt dialysis-assembled core particles /Shrader and Crothers 1989; I.C.A. Taylor and R.E. Kingston, unpubl.). This repeat pattern is also observed after cleavage with DNase (see below). We have employed this system (in addition to salt dialysis assembly; see Fig. 2B) because the nucleosome assembly components remain active during the analysis of factor binding. Thus, DNA fragments that might fortuitously dissociate from histones during binding studies may reassemble into nucleosomes. In addition, this system can efficiently assemble long DNA fragments into nucleosomes.

\section{GAL4 binds to nucleosome-assembled templates}

We first used mobility-shift analysis to determine the ability of GAL4 to bind to assembled templates. We analyzed several derivatives of GAL4, as we had shown in a previous study that transcriptional activation domains fused to GAL4 could help establish the basal transcription complex in competition with nucleosome assembly (Workman et al. 1991). This raised the possibility that these activation domains might have some effect on the structure of nucleosomes that might be reflected by altered binding of these GAL4 derivatives to assembled templates. The derivatives were purified from overexpressing bacterial strains and include the DNA-binding domain of GAL4 [GAL4(1-94)] as well as acidic activation domains fused to the DNA-binding domain /GAL4 $\mathrm{AH}$ and GAL4-VP16; Giniger and Ptashne 1987; Sa- 
dowski et al. 1988; Carey et al. 1990a; Workman et al. 1991). A 170-bp probe that contained five tandem repeats of the 17-bp GAL4-binding site was end-labeled and assembled into nucleosomes. This precise sequence has been shown to mediate potent transcriptional activation in both yeast and mammalian systems (Giniger et al. 1985; Webster et al. 1988). Note also that this probe is only long enough for a single nucleosome to form. The probe was either mock-assembled (Fig. 1A, - histones) or nucleosome-assembled (+ histones) to form templates for binding with increasing amounts of each GAL4 derivative. The formation of a nucleosome is evidenced by a specific complex on mobility shift gels (e.g., lane 3) that sediments at $11 \mathrm{~S}$ when analyzed by sucrose gradient analysis (data not shown; see Pina et al. 1990).

As GAL4(1-94) was added to naked DNA, each of the five sites became occupied until a low mobility complex formed that represents complete saturation of all the sites (Fig. 1A, lane 6). That complex migrated more slowly when the larger GAL4-AH and GAL4-VP16 de- rivatives were used (lanes 12 and 18, respectively). Interestingly, the GAL4 derivatives also were able to bind to the nucleosomal template. As each GAL4 derivative was added to the assembled probe, each of the five sites became occupied, forming complexes that had lower mobility than their counterparts on mock-assembled templates (e.g., cf. lanes 5 and 8). Correspondingly, when all of the sites became saturated, the resulting complex had a lower mobility than that with mock-assembled templates (e.g., cf. lanes 6-9, 12-15, and 18-21). This latter effect is visualized more easily in Figure 1B, in which a similar experiment is resolved on a longer gel. This observation suggests that the complexes generated by GAL4 derivatives binding to assembled templates retain at least part of the nucleosome. We confirmed that the GAL4 protein was present in these ternary complexes by performing in situ 1,10-phenanthroline-copper ion footprinting (data not shown; Kuwabara and Sigman 1987). Experiments similar to those shown in Figure 1 demonstrated that the GAL4 derivatives also were able to bind
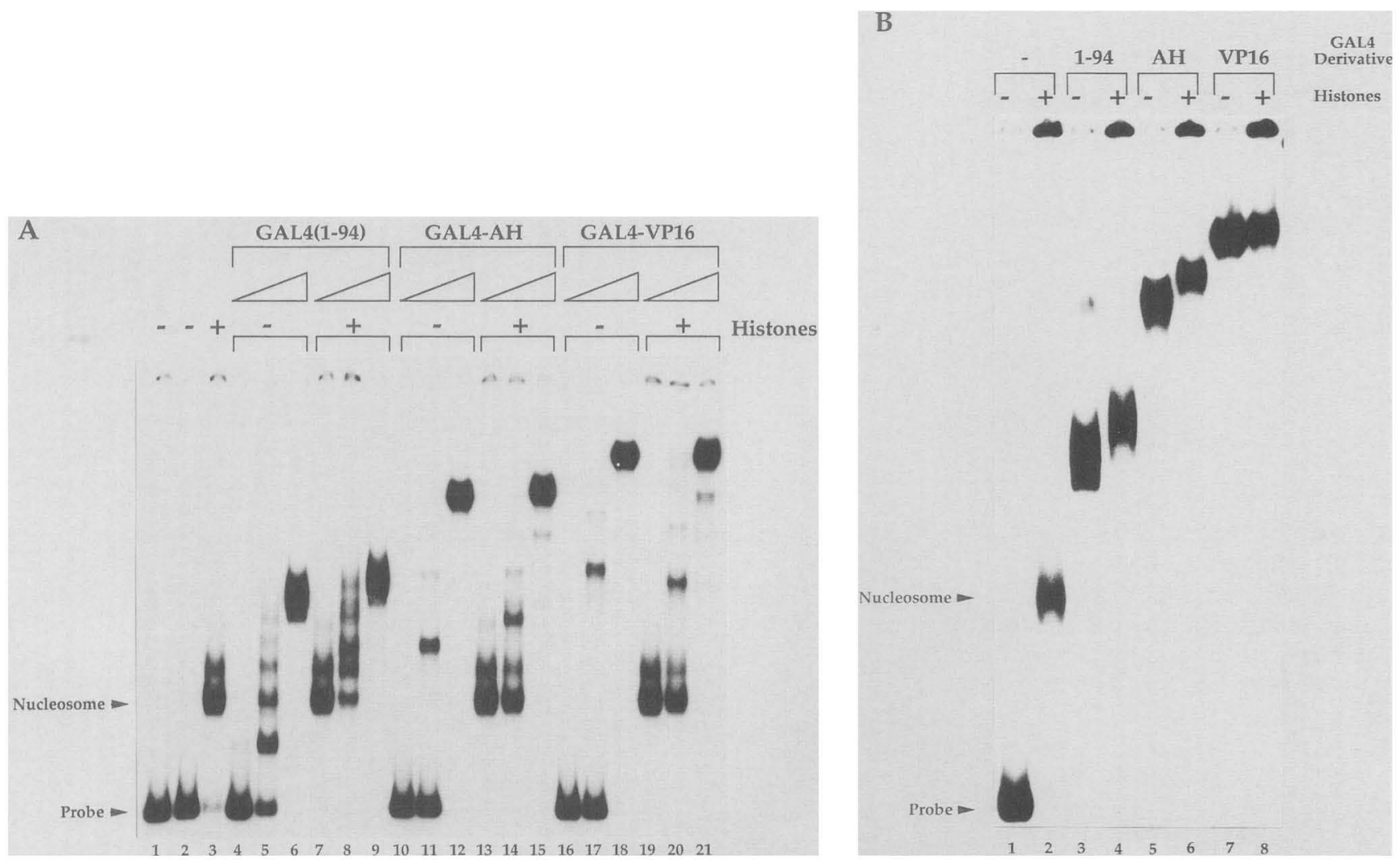

Figure 1. GAL4 derivatives can bind to nucleosomal templates. (A) Binding titration on mock-assembled (- histones) vs. nucleosome-assembled (+ histones) templates as assayed by mobility shift. The probe (1.6 $\mathrm{ng})$ is $170 \mathrm{bp}$ and contains five tandem GAL4 17-mer DNA-binding sites. Lane 1 is a binding reaction with buffer; lanes 2-21 contain the Xenopus egg heat-treated supernatant containing nucleosome assembly factors. All reactions contained $100 \mathrm{ng}$ of nonspecific plasmid as carrier DNA. Two hundred nanograms of HeLa core histones was added in marked lanes $(+)$, resulting in formation of a nucleosome $($ lanes $3,7,13$, and 19$)$. Tenfold increments of each GAL4 derivative were added to both mock-assembled (- histones) and nucleosomal templates. Total saturation of all the sites results in a single, low-mobility complex. Probe saturation occurs at 80 ng of GAL4(1-94) (lanes 6 and 9), 12 ng of GAL4-AH (lanes 12 and 15), and $29 \mathrm{ng}$ of GAL4-VP16 (lanes 18 and 21). (B) An experiment similar to $A$ except that the resulting complexes are resolved on a longer $(22 \mathrm{~cm})$ gel and frog histones (500 ng) are used. Amounts of proteins used: GAL4(1-94), $80 \mathrm{ng}$; GAL4-AH, $12 \mathrm{ng}$; GAL4-VP16, $29 \mathrm{ng}$. 
a single 17-bp GAL4-binding site assembled into nucleosomes (data not shown; see footprinting studies below).

\section{HSF is unable to bind to a nucleosomal template}

We then tested the ability of a second regulatory factor, $\mathrm{HSF}$, to bind to nucleosome-assembled templates. $\mathrm{Hu}$ man HSF was purified to homogeneity from HeLa cells (Schuetz et al. 1991). A 195-bp fragment of the human hsp70 promoter containing the wild-type heat shock element (HSE) was end-labeled and either mock-assembled (Fig. 2A, lanes 1-7) or nucleosome-assembled (Fig. 2A, lanes 8-14|, using the in vitro system. HSF binds to adjacent inverted repeats of the sequence $n$ GAAn (Amin et al. 1988; Xiao and Lis 1988), and the HSE used here has two perfect repeats and a third imperfect repeat (gGAAtaTTCccGACc). As decribed above, the labeled fragment is only long enough for a single nucleosome to form (lane 8). Increasing amounts of purified HSF were added to each set of reactions and allowed to interact with the templates for $30 \mathrm{~min}$. HSF readily binds to the mock-assembled templates, forming a low mobility complex that saturates the probe at $20 \mathrm{ng}$ of HSF. In

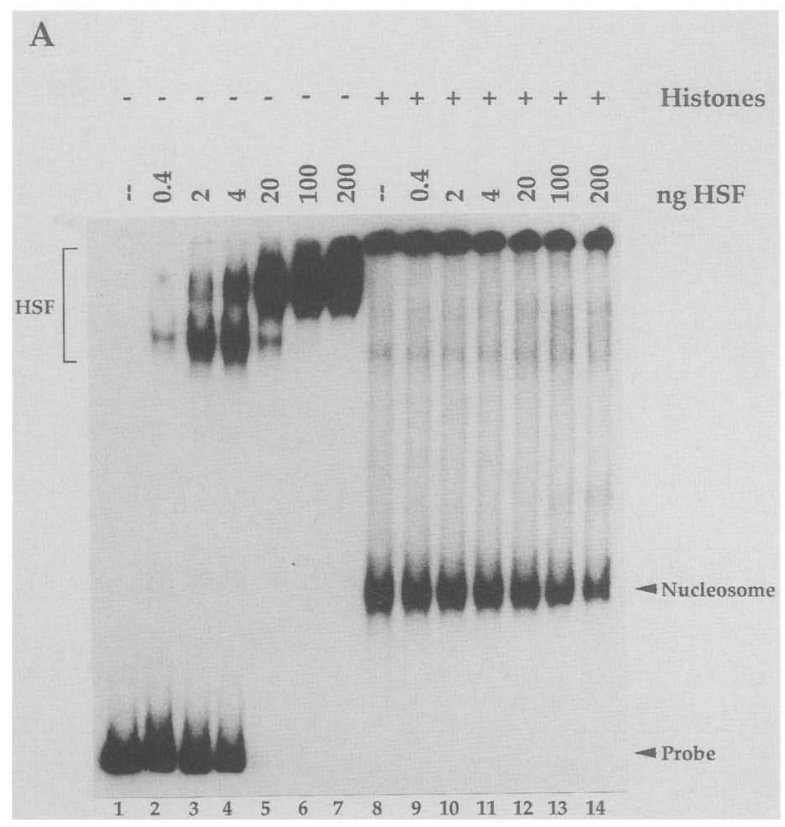

contrast, when the template was completely assembled into a nucleosome, HSF was unable to bind to an HSE containing three $n \mathrm{GAA} n$ repeats even at $200 \mathrm{ng}$, as evidenced by the fact that no low mobility complex appears and that the nucleosome band remains approximately constant (there is a slight decrease in intensity of the nucleosome band at high levels of HSF that we believe to be caused by the addition of the detergent NP-40, which is in the HSF fractions). Note that there is some material that did not enter the gel when frog histone preparations were used to assemble nucleosomes (Figs. 1B and 2A). This material was not seen when HeLa histone preparations were used (e.g., Fig. 1A); therefore, HeLa histones were used in all subsequent experiments.

Because six inverted $n$ GAAn repeats appear necessary to create an HSE that will function at a distance (Bienz and Pelham 1986; Greene and Kingston 1990), we then tested binding of HSF to an assembled template containing six repeats. For this experiment, nucleosomal templates were gradient-isolated after being assembled by histone transfer from HeLa cell genomic nucleosome cores by salt dialysis (Fig 2B; Rhodes and Laskey 1989). Gradient-isolated templates were phenol-extracted for

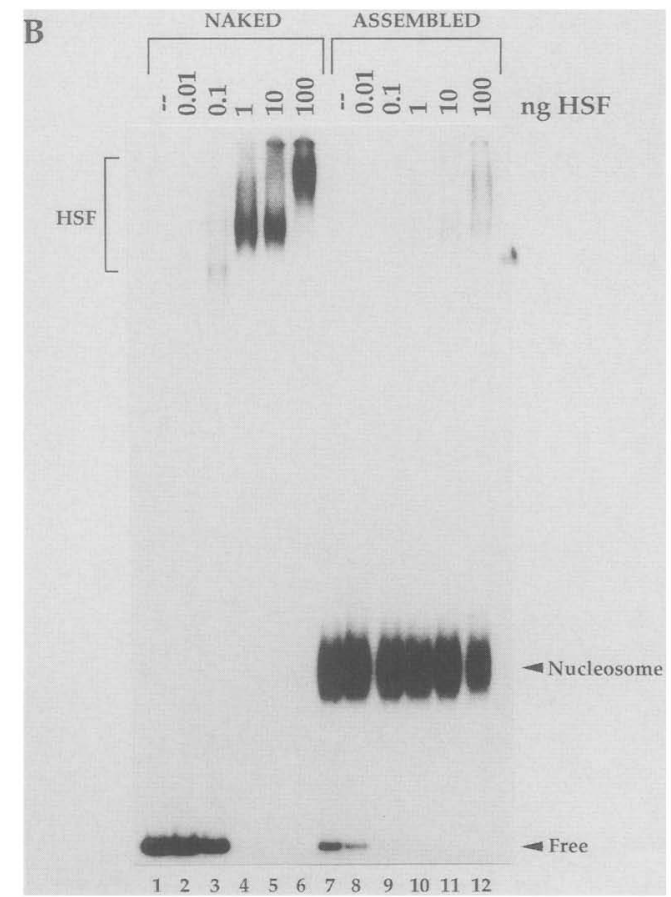

Figure 2. Human HSF cannot bind to nucleosomal templates. (A) A 195-bp labeled fragment 4 ng) containing a HSE with three $n$ GAAn repeats was either mock-assembled (- histones, lanes $1-7)$ or nucleosome-assembled $(+$ histones, lanes 8-14) with frog erythrocyte histones (500 ng). Reactions also contained $100 \mathrm{ng}$ of pUC18 as carrier DNA. Purified human HSF (as indicated) was added and incubated for an additional $30 \mathrm{~min}$ at $30^{\circ} \mathrm{C}$, and the resulting complexes were analyzed by mobility-shift assay. The position of the complexes formed by HSF binding to naked DNA is indicated, as is the position of the single nucleosome. $(B)$ A 155 -bp labeled fragment (from plasmid pGT/EHSE) containing a HSE with six $n$ GAAn repeats was assembled into nucleosomes by histone transfer from HeLa nucleosome core particles at $2 \mathrm{M} \mathrm{NaCl}$, followed by slow dialysis to $100 \mathrm{mM} \mathrm{NaCl}$ (see Materials and methods). The subsequently gradient-purified nucleosomes were used directly in binding reactions (assembled) or after extraction of the histone proteins (naked). Binding reactions contained the amount of HSF indicated and were performed under conditions identical to those in $A$ (except that the heat-treated egg supernatant was replaced with the appropriate buffer). The positions of the free probe (free), the nucleosome core particles (nucleosome), and the HSF-containing complexes (HSF) are indicated. 
use as a naked DNA control (Fig. 2B, lanes 1-6). The input nucleosomal probe consisted of a mixture of assembled DNA ("nucleosome," Fig. 2B, lanes 7-12) and a small amount of free DNA that had dissociated from histones during the isolation procedure ("free"). At low concentrations of HSF, free DNA was shifted to an HSFcontaining complex. In contrast, even at high concentrations of HSF the intensity of the nucleosome band remained essentially constant, indicating that HSF could not bind to the extended HSE on the assembled probe. Taken together, these data demonstate that HSF could not bind to a nucleosomal template and that this lack of binding was not the result of inhibition by free histones. Thus, HSF and GAL4 differ in their ability to bind to nucleosome-assembled templates. DNase footprint analysis was used to further characterize these interactions.

\section{Factor binding to nucleosome-assembled plasmid DNA}

To determine the binding affinities of GAL4 and HSF for naked versus nucleosomal DNA, we performed binding titrations assayed by DNase I footprinting. A dissociation constant can be assigned using this protocol by determining the amount of a protein required for a halfmaximal footprint under conditions of limiting template concentration (Johnson et al. 1979; Brenowitz et al. 1986). In these experiments the templates were $\sim 3000$ bp in length. There is no evidence for precise positioning of nucleosomes on these extended templates. The lack of specific positioning makes it difficult to directly analyze the extent of nucleosome assembly; however, several lines of evidence argue that these templates are fully assembled. First, some histone-specific bands are evident in footprinting studies after nucleosome assembly of these templates. Second, micrococcal nuclease and template supercoiling assays performed under reaction conditions identical to those used here (i.e., $200 \mathrm{ng}$ of HeLa core histones) assemble closed circular plasmid DNA into nucleosomes at a density of $>1$ nucleosome per 200 bp of DNA (Workman et al. 1991 and data not shown). Furthermore, identical conditions and reagents were used in the previous mobility-shift experiments (Figs. 1 and 2), as well as in footprinting studies using probes that contain artificial nucleosome-positioning sequences (see below). Both analyses clearly show that the templates contain nucleosomes.

A template containing either one or five GAL4-binding sites was assembled into nucleosomes, and binding by the GAL4-AH fusion protein was determined by DNase footprinting (Fig. 3). With naked DNA, $1.2 \mathrm{ng}(2$ units, with 1 unit defined as the amount required to half-saturate the template) of GAL4-AH resulted in a virtually complete footprint on both the single (lane 3) and five (lane 15) GAL4 site probes, confirming that GAL4 does not bind to DNA cooperatively. When the single GAL4 site template was assembled into nucleosomes, significant protection of the site was observed at

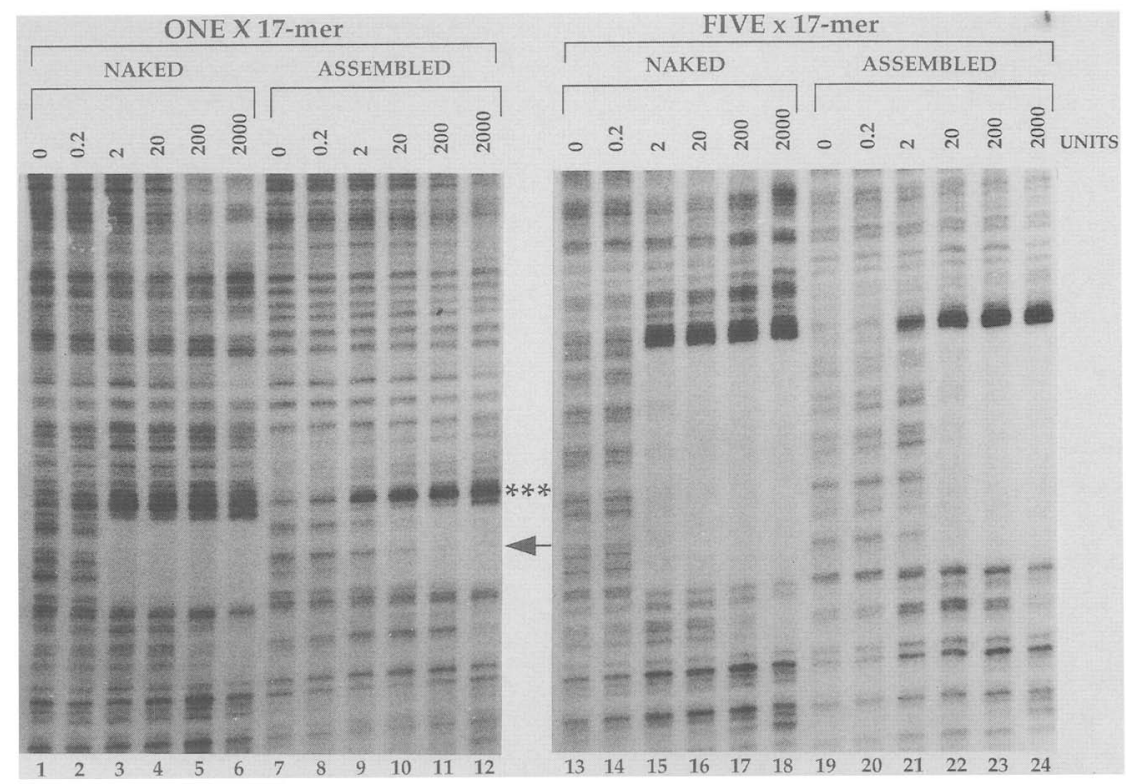

Figure 3. GAL4 binding to nucleosomal templates containing one and five 17 -mers. Approximately $900 \mathrm{pg}\left(2 \times 10^{-11} \mathrm{M}\right.$ final concentration) of a 3000-bp labeled fragment containing either one GAL4-binding site (ONE $\times 17$-mer, lanes 1-12) or five sites (FIVE $\times$ 17-mer, lanes 13-24) were either mock-assembled (naked, lanes 1-6 and 13-18) or nucleosome-assembled with $200 \mathrm{ng}$ of HeLa core histones (lanes 7-12 and 19-24). Reactions also contained 100 ng of pUC-18 as carrier DNA. Increasing amounts of GAL4-AH were titrated onto each set of templates, and binding was assayed by DNase I footprinting. GAL4-AH amounts are described in units of binding activity, with 1 unit $(0.6 \mathrm{ng})$ defined as the amount of protein required for a half-maximal footprint on naked DNA. The arrowhead marks a band within the footprint of the single GAL4 site on nucleosomal templates. The asterisks (*) denote the hypersensitive site that appears at 2 units of GAL4-AH (see text). The two panels are from the same exposure of the same gel. 
200 units of GAL4 and complete protection required 2000 units (e.g., note band marked by arrowhead, lanes 7-12 in Fig. 3). Note that a hypersensitive site (asterisks, lane 9) appeared at 2 units of GAL4-AH, indicating some interaction of GAL4-AH with the nucleosomal template at concentrations 2 orders of magnitude below that required for a significant footprint. This might be caused by a nonhomogeneous assembly of GAL4-binding sites into nucleosomes (e.g., some sites might be in linker DNA). This more accessible class of sites would account for the hypersensitivity, whereas most of the GAL4 sites would be less accessible because of their placement in a nucleosome. This hypothesis is supported by studies on templates where nucleosomes are positioned (see below).

Interestingly, assembled templates containing five GAL4 sites bound GAL4-AH better than templates with one GAL4 site (Fig. 3, cf. lanes 19-24 with lanes 7-12). Although hypersensitivity could also be observed on these templates at 2 units of GAL4-AH, a significant footprint was seen at 20 units of GAL4-AH and complete protection occurred at 200 units. Thus, GAL4 could bind to five sites in a nucleosome with a higher affinity than it binds to one site. Consistent with this observation, the affinity of GAL4-AH for a nucleosomal template with two GAL4 sites was intermediate to one and five sites (data not shown). Therefore, although the affinity of GAL4 to naked DNA is not affected by multimerization of binding sites, the affinity of GAL4 for nucleosomal templates is increased by multimerization of binding sites.

Consistent with the mobility-shift experiments (Fig. 2), footprint titration experiments using 3000-bp templates demonstrated that HSF could not bind to nucleosomal DNA. Not even a partial footprint was seen at HSF concentrations 1000-fold higher than those needed for binding to naked DNA (Fig. 6, below).

\section{Factor binding to single rotationally phased nucleosomes}

The 3000-bp assembled templates contain nucleosomes that are not homogeneously positioned along the DNA. Thus, it is possible that the observed difference between HSF and GAL4 in binding to nucleosomal templates is merely a function of a difference in the positions of the nucleosomes on the probes. To address this possibility we constructed templates that placed a 20-bp artificial nucleosome-positioning sequence adjacent to the HSFand GAL4-binding sites. These positioning sequences (named GT; Shrader and Crothers 1989) are thought to create a bend in the DNA that encourages the rotational phasing of DNA on the surface of nucleosomes. In addition, to ensure that the binding elements were contained within the nucleosome, we centered the elements in fragments only long enough to form a single nucleosome $(\sim 150 \mathrm{bp})$.

A 155-bp fragment containing the extended HSE adjacent to the positioning sequence was either mock- or nucleosome-assembled and used as a template for DNase footprinting. Rotational phasing of the nucleosome can be seen by comparing the DNase digestion pattern of the mock- versus the nucleosome-assembled reaction (Fig. 4A, cf. lanes 1 and 7/. DNA that is wrapped around a histone core has a 10-bp repeat of DNase-sensitive sites that results from the minor groove being accessible on the outside of the nucleosome core (Fig. 4A,C, asterisks). When the minor groove faces inward toward the core, protection from DNase results (Fig. 4A,C, arrows). Note that in our nucleosomal template this repeat pattern continues through the HSE, confirming that this binding site is in fact part of the nucleosome.

Increasing amounts of purified HSF were titrated into the mock-assembled (Fig. 4A, lanes 1-6) and the nucleosome-assembled (lanes $7-12$ ) reactions. One nanogram of HSF (10 units, with 1 unit defined as the amount needed for a half-maximal footprint) gave a complete footprint on mock-assembled (naked) DNA (lane 3). No hint of binding was seen on a nucleosomal template, even at 1000 units of HSF (lane 12). Experiments with the MMTV promoter suggest that the orientation of the glucocorticoid receptor (GR)-binding site with respect to the surface of the histone core may be critical to allow binding of glucocorticoid receptor to a nucleosomal template (Richard-Foy and Hager 1987; Perlmann and Wrange 1988; Pina et al. 1990; Archer et al. 1991). In light of this possibility we rotated the orientation of the optimized HSE relative to the histone core by altering the distance between the HSE and the positioning sequence by inserting 4 bp and deleting 4 and 12 bp (Fig. 4B). In each case, identical results were obtained; HSF showed no inclination to bind to a nucleosomal template.

The artificial positioning sequence also succeeded in placing the single GAL4 site within a nucleosome as we observe a distinct DNase hypersensitive-protection repeat extending through the site in the 147-bp assembled templates (Fig. 5A, cf. lanes 1 and 7; Fig. 5B). A titration with increasing amounts of GAL4-AH was performed with both mock-assembled (lanes 1-6) and nucleosomeassembled (lanes 7-12) templates. Again, $1.2 \mathrm{ng}$ (2 units) of GAL4-AH gave a near-complete footprint on naked DNA. As was observed in Figure 3, GAL4-AH was able to bind to the nucleosomal template, giving a significant footprint at 200 units and a complete footprint at 2000 units. Note that in contrast to results obtained with a randomly assembled template (Fig. 3), no hypersensitive site appears at low ( 2 or 20 units) GAL4 concentrations. This observation supports the notion that the hypersensitivity reflected a subpopulation of molecules where the GAL4 site was either near the end of the nucleosomal DNA or in a linker region.

We altered the orientation of the GAL4 site with respect to the positioning sequence by inserting $4 \mathrm{bp}$ and deleting 5 and $10 \mathrm{bp}$. Interestingly, GAL4-AH showed an equal ability to bind to all of these nucleosomal templates (data not shown), suggesting that the exact orientation of the 17-mer with respect to the histone core is not critical. GAL4 has been shown to contact the sugar phosphate backbone of the 17-mer at bases that cover a complete turn of the B-form double helix /Carey et al. 

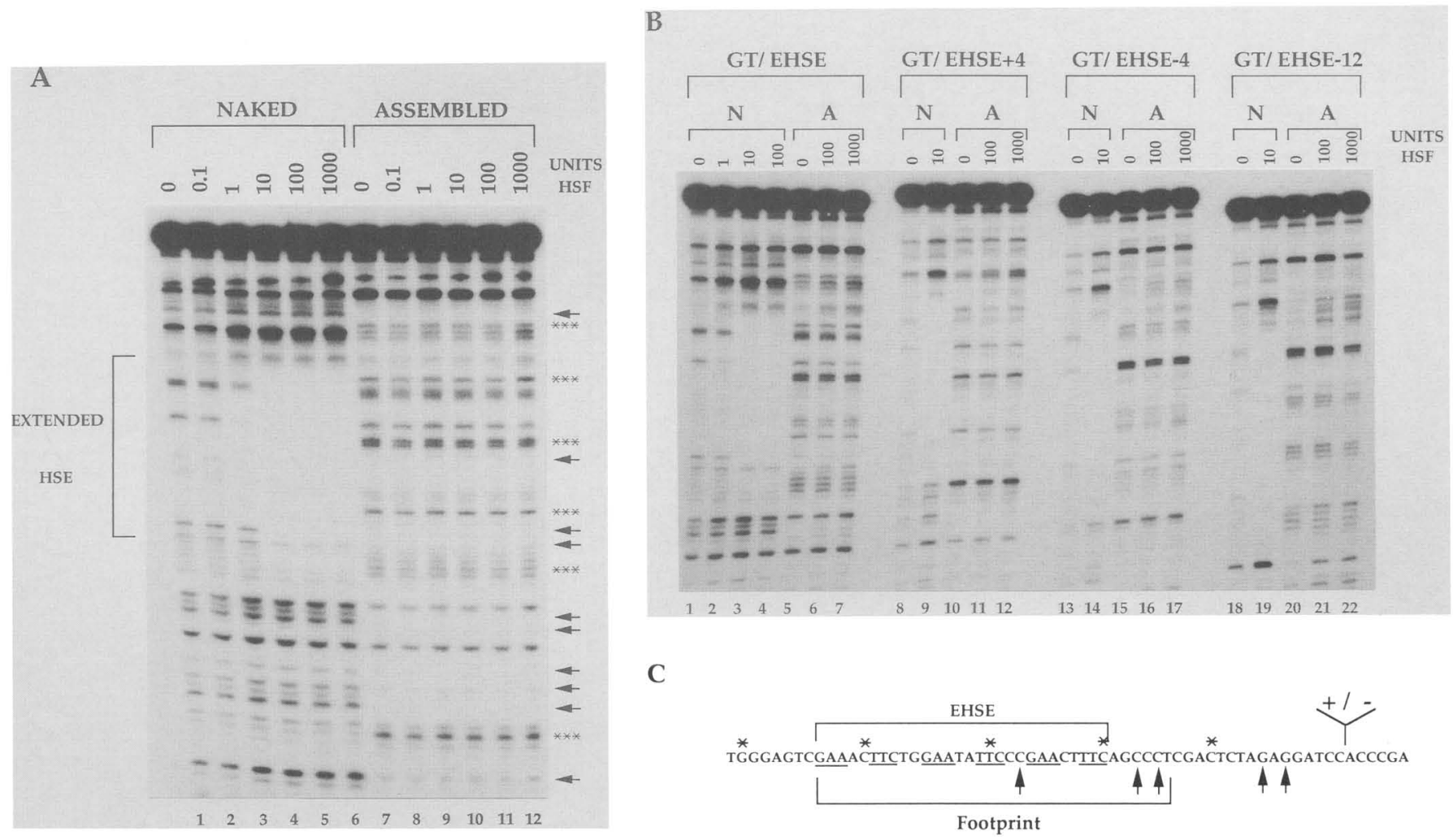

Figure 4. Human HSF does not bind to a phased nucleosome. (A) Binding titration of HSF on a 155-bp labeled fragment from plasmid pGT/EHSE that contains a 20-bp artificial nucleosome-positioning sequence (GT) adjacent to the extended HSE (six $n$ GAAn repeats). This probe ( $50 \mathrm{pg}, 2 \times 10^{-11} \mathrm{M}$ final concentration) was either mock-assembled (naked, lanes 1-6) or assembled with $200 \mathrm{ng}$ HeLa core histones (lanes 7-12). pUC18 (100 ng) was included in each reaction as carrier DNA. Arrows mark sites that become protected upon nucleosome assembly; asterisks (*) denote sites that become hypersensitive to the DNase. These regions occur at 10-bp intervals, as confirmed by resolving a ladder of naked DNA cut at every base pair by hydroxy radicals in adjacent lanes (not shown). HSF amounts are described in units, with 1 unit $(0.1 \mathrm{ng})$ defined as the amount required for a half-maximal footprint on naked DNA (lane 3). (B) Footprinting on templates that rotate the extended HSE relative to the nucleosome-positioning sequence. Templates include labeled fragments from pGT/EHSE (lanes 1-7, see A); pGT/EHSE + 4 (lanes 8-12), which has 4 bp inserted between the positioning sequence and the extended HSE; pGT/EHSE-4 (lanes 13-17) and pGT/EHSE-12 (lanes 18-22), which have 4 bp and 12 bp, respectively, deleted between the positioning sequence and the extended HSE. Fifty picograms (0.5 fmoles) of each probe, along with carrier DNA (100 ng), was either mock-assembled (N) or assembled into nucleosomes with $200 \mathrm{ng}$ of HeLa core histones (A). Amounts of HSF added to the templates are described in units of binding activity. $(C)$ A portion of the probe containing the extended HSE. Underlined bases show the core of each of the $n$ GAAn inverted repeats. Asterisks (*) show bases hypersensitive to cleavage by DNase on nucleosomeassembled DNA and thus are positioned facing away from the nucleosome. Arrows are protected bases, facing in toward the nucleosome. (Footprint) The bases protected by HSF on naked DNA. The $+/-$ symbol denotes where base-pair insertions and deletions were made to change the relative position of the EHSE in the nucleosome. The probe was labeled at the $3^{\prime}$ end as depicted here.

1989). Thus, part of the region of the 17 -mer contacted by GAL4 must always be on the outside of the nucleosome. The ability of GAL4 to bind regardless of the rotational position of the nucleosome might therefore be explained by postulating that GAL4 is equally capable of initiating binding at several base pairs on either side of the DNA helix.

In summary, three different protocols (mobility-shift analysis and DNase footprinting on rotationally phased and nonphased nucleosomal templates) all demonstrate that HSF cannot bind to nucleosomal templates, whereas GAL4 is able to bind to these templates. Footprint titration experiments yielded a dissociation constant $\left(K_{\mathrm{d}}\right)$ of $\leqslant 4 \times 10^{-11} \mathrm{M}$ for HSF on naked DNA (Fig.
$4 \mathrm{~A}$; see Materials and methods). HSF has at least a 1000 fold lower affinity for nucleosomal templates (Fig. 4). The dissociation constant of GAL4 for either one site or five sites on naked DNA is $\sim 10^{-9} \mathrm{M}$ as calculated from titration experiments such as those decribed in Figure 3 and $3 \times 10^{-9} \mathrm{M}$ as calculated by others (S. Liang and $\mathrm{M}$. Ptashne, pers. comm.). Thus, GAL4 binding to naked DNA is intrinsically weaker than HSF binding, yet GAL4 was less affected by nucleosomes. Nucleosomes did alter GAL4 binding, however, as the affinity of binding to a single GAL4 site was $\sim 100$-fold lower on a nucleosomal template than on naked DNA (most clearly seen in Fig. 5; see also Fig. 3). Binding to five GAL4 sites had a 10-fold lower affinity on assembled templates (Fig. 


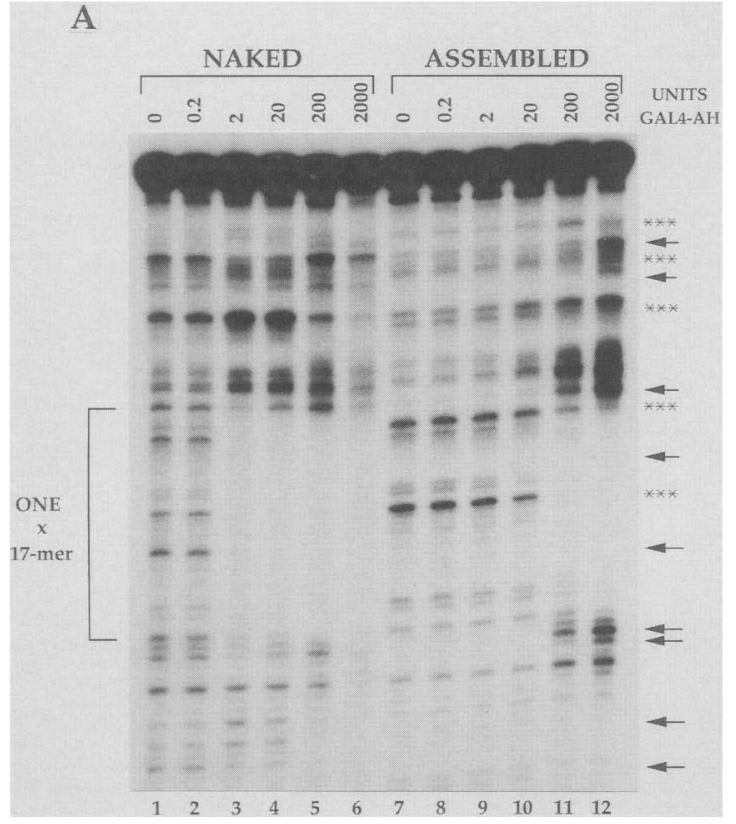

3). Therefore, it appears that GAL4 can bind to five sites on nucleosomal templates $\sim 1$ order of magnitude better than it binds to one site. It is important to note that this conclusion is tempered somewhat by our inability to measure rigorously affinity of GAL4 to one site and five sites under identical conditions. The most quantitative measurement of affinity of GAL4 to one site is accomplished by using positioned nucleosomes (Fig. 5)-conditions that cannot be used for five sites because we are unable to position a nucleosome across all five sites. The most rigorous measure of affinity for five sites uses long templates (Fig. 3) where binding to one site is not homogeneous, resulting in a binding isotherm for one site that is difficult to interpret but that is consistent with lower affinity binding.

\section{TFIID facilitates HSF binding to nucleosomal templates}

The observed inability of HSF to bind to its site in a nucleosome is consistent with in vivo footprinting data suggesting that the HSE is free from nucleosomes in many heat shock promoters (Wu 1980, 1984; Keene et al. 1981; Costlow et al. 1985). Interestingly, factors have been found to be bound constitutively to the TATA-cap region of the Drosophila hsp 70 and hsp26 and human hsp70 promoters (Wu 1984; Gilmour and Lis 1986; Thomas and Elgin 1988; Abravaya et al. 1991), raising the possibility that the TATA-binding factor (TFIID) alone, or the entire core transcription complex, might exclude nucleosomes from the nearby HSE. We used the nucleosome assembly system to test whether TFIID alone could facilitate binding by HSF.

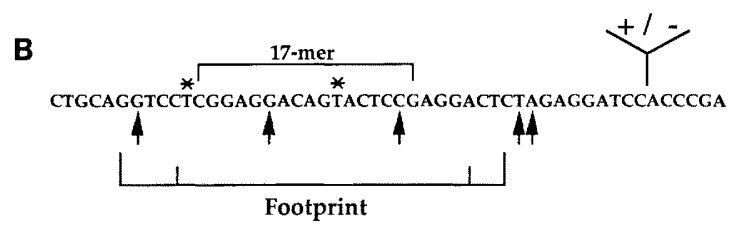

Figure 5. Binding of GAL4 to a positioned nucleosome. $(A)$ Binding titration of GAL4-AH on a 147-bp labeled fragment from plasmid pGT/GALl that contains a 20 -bp artificial nucleosome-positioning sequence $(\mathrm{GT})$ adjacent to a single GAL4 17-mer. Fifty picograms $\left(0.5\right.$ fmoles, $2 \times 10^{-11}$ $M$ final concentration) of the probe was either mock-assembled (naked, lanes 1-6) or nucleosome-assembled (lanes 712) with $200 \mathrm{ng}$ of HeLa core histones. Carrier DNA | $100 \mathrm{ng}$ of pUC-18) was included as before. Arrows mark sites that become protected specifically upon nucleosome assembly; asterisks $\left({ }^{*}\right)$ denote sites that become DNase hypersensitive. Note that these sites, which occur at 10 -bp intervals, extend through the GAL4-binding site. Amounts of GAL4 $\mathrm{AH}$ added to the templates are defined in units $(1$ unit $=0.6 \mathrm{ng}$; see text and legend to Fig. 3$).(B)$ A portion of the single GAL4 site (17-mer) probe. Symbols are the same as in Fig. $4 \mathrm{C}$. The outer footprint brackets show the region protected by GAL4 on naked DNA; the inner brackets show that region on nucleosome-assembled templates.

The design of the experiment was as follows: Bacterially produced yeast TFIID (byTFIID) was bound to the naked template, which was then assembled into nucleosomes. For the template we placed the extended HSE 20 bp upstream of the human $h s p 70$ TATA site, thereby mimicking the Drosophila hsp70 promoter. Subsequently, purified HSF was added to the nucleosomal templates, with binding assayed by DNase I footprinting (Fig. 6). As no artificial positioning sequences were present, the assembled nucleosomes were not phased (Fig. 6, cf. lanes 1 and 2), therefore recreating the presumed condition of the wild-type promoter. We tested two different concentrations of byTFIID in our protocol: $0.1 \mu \mathrm{g}$ did not give a complete footprint over the TATA element (lanes 5-7), whereas $0.2 \mu \mathrm{g}$ gave maximal protection (lanes 8-10). As noted above, HSF alone was unable to bind to the assembled template, even when 1000 units (100 ng) of purified protein was added (lane 4). However, when the TATA element was fully occupied with byTFIID before assembly, postassembly binding of HSF was greatly facilitated (cf. lane 8 with lanes 9 and 10 ), with a complete footprint resulting at 100 units of purified HSF. Interestingly, when only partial occupation of the TATA element by byTFIID was observed, HSF was unable to bind to all the nucleosomal templates, as only a partial footprint was observed even at 1000 units of HSF (lane 7). The direct correlation between the percentage of TATA boxes occupied by byTFIID on nucleosomal templates and the ability of HSF to bind to those templates suggests that specific binding of TFIID is required to facilitate binding of HSF to this nucleosomal promoter.

As a control we tested a promoter possessing a mu- 


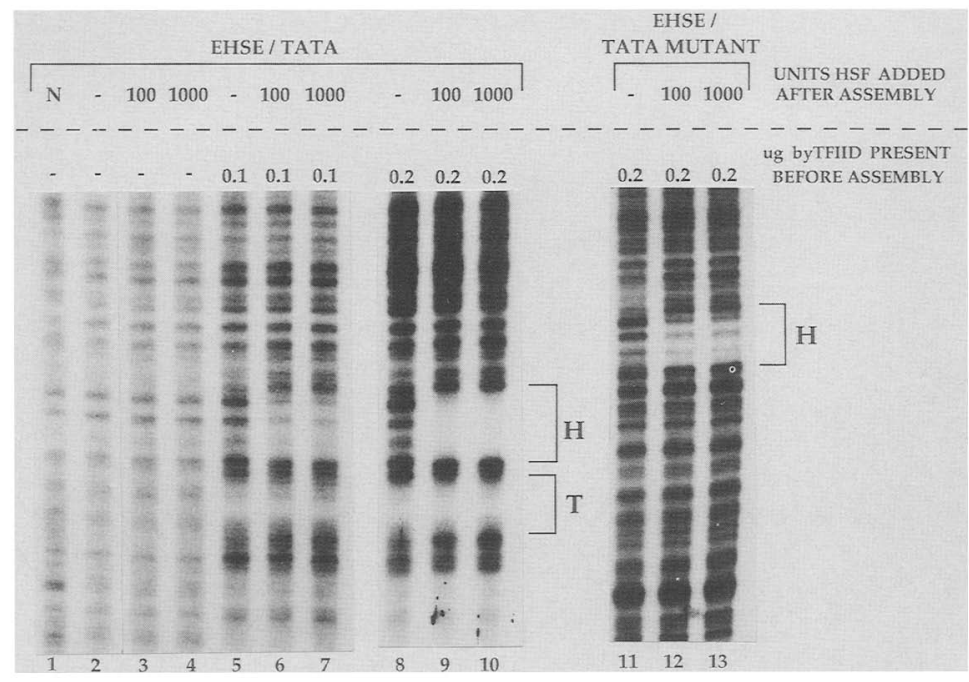

Figure 6. TFIID facilitates binding of HSF to nucleosomal templates. Bacterially produced yeast TFIID (byTFIID) was bound to 3000 -bp templates (4 ng probe plus $100 \mathrm{ng}$ of pUC-18 as carrier DNA) that either contained the wild-type $h s p 70$.TATA site (lanes $1-10$ ) or a mutant TATA site (lanes 11-13) adjacent to the extended HSE. Reactions in lanes 1-4 received no byTFIID. Subsequently, the templates were assembled into nucleosomes (with the exception of lane 1, marked $\mathrm{N}$, which was mock-assembled) with $200 \mathrm{ng}$ of HeLa core histones. After assembly, purified human HSF was added to those lanes so marked. Amounts of HSF are shown ( 1 unit $=0.1 \mathrm{ng}$; see text and legend to Fig. 4A). Binding was assayed by DNase footprinting. (T) TATA site $_{;}(\mathrm{H})$ extended HSE. The extended HSE of the TATA mutant construct is located $\sim 60$ bp farther away from the labeled restriction site than in the wild-type TATA construct. tated TATA element for facilitated binding of HSF in the presence of byTFIID. As mentioned above, HSF could not bind to the HSE of this construct in the absence of TFIID (data not shown), although a partial footprint of HSF to this promoter was observed when $0.2 \mu \mathrm{g}$ of byTFIID was present (lanes 12 and 13), indicating that HSF binding is facilitated on some of the templates by TFIID in the absence of a TATA box. Thus, only partial facilitation of HSF binding is observed in the absence of a TATA box at a TFIID concentration that completely facilitates binding of HSF when the HSE is adjacent to a TATA box (cf. lanes 9 and 10 with 12 and 13). We believe that this activity of byTFID in the absence of a TATA box reflects the well-documented ability of TFIID to bind to random DNA sequences (Hahn et al. 1990; Singer et al. 1990). These data imply that TFIID was able to exclude nucleosomes from the HSE and suggest an explicit model for how HSF binding to heat shock promoters is facilitated in vivo.

\section{Discussion}

Processes such as transcription, replication, and recombination all require DNA-binding proteins to function in the context of chromatin. An understanding of the ability of these proteins to bind to nucleosomal DNA is therefore critical to understanding these processes. $\mathrm{Nu}$ merous studies imply that nucleosomes can affect DNA binding by proteins. In this report we examine the activity of two well-characterized transcriptional activators, human HSF and derivatives of yeast GAL4, when these proteins are confronted with their recognition sequences in nucleosomes. We demonstrate that nucleosomes have a dramatic inhibitory effect on the binding of HSF yet only moderately inhibit the binding of GAL4. Thus, different regulatory factors interact differently with nucleosomes. Despite these differences, the binding of both GAL4 and HSF to nucleosomal DNA can be facilitated; in the case of GAL4, by increasing the number of GAL4binding sites; in the case of HSF, by adjacent TFIID bind- ing. We argue that these mechanisms of facilitated binding of proteins to nucleosomal DNA play an important role in the regulation of gene expression.

\section{HSF function}

Our data indicate that human HSF has an affinity for its recognition sequence in a nucleosome that is at least 3 orders of magnitude less than for that site in naked DNA. Under the conditions used here, we were never able to observe even partial binding of HSF alone to the HSE in a nucleosomal context. This observation helps to explain the evolutionarily conserved open chromatin structure found in the promoters of the major heat shock genes. These genes play a critical role in the response of a cell to stress. Such a response must be rapid to ensure the viability of the cell, and HSF mediates this transcriptional response. Therefore, it follows that HSF must find and bind to a given HSE quite rapidly after stress induction.

Given the data presented here, it is clear that the only way to ensure that HSF will bind rapidly to the HSE is for the cell to maintain that region in a nucleosome-free state. One proposed mechanism for accomplishing this nucleosome exclusion is based on studies of the Drosophila hsp70 promoter, in which the HSE is located relatively close to the TATA box (Wu 1984). This model suggests that the constitutively bound TATA factor TFIID, or a complex including that factor, is able to exclude nucleosomes. We demonstrate that the presence of TFIID alone on a nucleosomal template will facilitate the binding of HSF to a nearby HSE (Fig. 6). The presence of TFIID increases the affinity of HSF for nucleosomal DNA by at least 2 orders of magnitude. Further experiments are required to determine whether TFIID has this effect because it displaces nucleosomes or uses some other mechanism to render the DNA accessible to HSF.

Previous studies have suggested that upstream sequences are necessary in conjunction with the TATA box for creation of a complete nuclease hypersensitive 
region in certain heat shock promoters (Costlow et al. 1985; Brown et al. 1988). Thus, factors other than TFIID are probably also involved in facilitating binding of HSF to certain HSE sequences in vivo. For example, we have found that binding of TFIID to the TATA box at -30 of the human $h s p 70$ promoter does not facilitate binding of HSF to the naturally found HSE at -100 /data not shown). Facilitation of HSF binding to this sequence might require (in addition to TFIID) the upstream factors Spl and CP1, which bind between the HSE and the TATA box in this promoter and are required for constitutive (i.e., absence of heat shock) promoter function (Greene et al. 1987; Wu et al. 1987; Abravaya et al. 1991).

\section{GAL4 implications}

In contrast to HSF, the derivatives of GAL4 bind quite readily to their sites in a nucleosome, albeit not as well as to naked DNA. As expected, GAL4 did not show any preference between one 17-mer and five such sites on naked DNA $\left(K_{\mathrm{d}}\right.$ of $\left.\sim 10^{-9} \mathrm{M}\right)$, confirming that GAL4 does not bind cooperatively (Carey et al. 1990b). Interestingly, when the templates were assembled into nucleosomes, the GAL4 proteins bound to a template with five sites with higher affinity than to a template with one site (Figs. 3 and 5). Binding of GAL4 to a nucleosomal template is not a classical cooperative interaction as there are three components involved (GAL4, DNA, and histones). Rather, binding to five sites in a nucleosomal context is "facilitated" relative to a single site.

To explain the increased affinity of GAL4 to sequences containing two or five sites, we imagine that the GAL4 dimer might bind weakly to the most accessible 17 -mer, thereby weakening the interaction between the nucleosome and adjacent DNA. This might increase the accessibility of the remaining GAL4-binding sites and thus facilitate binding. This hypothesis is supported by the dramatic hypersensitive sites on one side of the GAL4 footprint on nucleosomal DNA, indicating that this adjacent DNA is very accessible. Our gel shift experiments (Fig. 1A and B) suggest that GAL4 can form a ternary complex with a nucleosome. Experiments to determine whether this complex contains a complete histone octamer or only a fraction of the octamer have not yet been done.

At present, it is unclear whether the ability of GAL4 to bind to its site in a nucleosome is required for its transcriptional activation function in yeast (Chasman et al. 1990). However, the ability of GAL4 to bind to nucleosomes fits well with the characteristics of GAL4 transcriptional stimulation studied in vitro. For example, these in vitro studies have suggested that the GAL4-AH derivative may interact with and stabilize the binding of TFIID (Horikoshi et al. 1988). Furthermore, both GAL4 AH and GAL4-VP16 can promote the formation of basal transcription complexes in competition with nucleosomes (Workman et al. 1991). Thus, GAL4 seems to function early in the transcription initiation pathway. For GAL4 to play this role in vivo, it might well be required before TFIID binding (Selleck and Majors 1987), and thus an ability to bind to nucleosomes may be critical.

\section{Facilitated binding of transcription factors to nucleosomal DNA}

HSF and GAL4 differ dramatically in their ability to bind nucleosomal DNA. However, both exhibit facilitated binding to these templates, suggesting that this might be a general means by which critical regulatory factors gain access to a promoter contained in nucleosomes. Furthermore, the data presented above argue that a variety of mechanisms are used to facilitate binding to nucleosomes. Previous studies have shown that the transcription factor NF1 is unable to bind to its site within a nucleosome that is positioned on the MMTV promoter. In contrast, the GR is able to bind to the glucocorticoid response element (GRE) on this promoter (Perlmann and Wrange 1988; Pina et al. 1990; Archer et al. 1991). This binding has been proposed to rely on the rotational phasing of the nucleosome, although this has not yet been tested by altering that phasing. In vivo evidence has suggested that, upon hormonal induction, binding of GR to the GRE alters the nucleosome array to allow subsequent binding of NF1 and full transcriptional induction (Cordingley et al. 1987). Although there is not yet direct evidence that GR can facilitate NF1 binding, such facilitation may occur in a manner analogous to the facilitation of HSF by TFIID that we report here. Thus, facilitated binding to nucleosomes may be important in allowing numerous regulatory transcription factors to interact productively with nucleosomal promoter DNA.

Facilitated binding to nucleosomes may be relevant to enhancer function. For example, multiple GAL4 sites function significantly better as an enhancer than a single GAL4 site (Webster et al. 1988). This enhancer activity correlates with the binding activity of GAL4 on nucleosomal templates that we report here. Furthermore, facilitated binding fits well with the "enhanson" model for enhancer activity, which states that single transcription factor-binding sites that usually only function well in proximal promoter locations may function as distal enhancer elements when those sites are multimerized (Ondek et al. 1988). These data have been interpreted as implying that multiple interactions between transcription factor activation domains are required for transcriptional stimulation to occur from a distance, and in vitro studies are consistent with the theory that there is an important synergy between activation domains (for review, see Lewin 1990). On the basis of the results we report here, however, it is possible that enhancers may use multimerized sites in part to promote facilitated transcription factor binding to these chromatin-embedded recognition sequences, thus allowing function of the attached activation domains.

\section{Differential roles of DNA-binding domains in chromatin}

Sequence-specific transcription factors have been de- 
scribed as "modular," that is, composed of two parts: a transcriptional activating domain and a DNA-binding domain. Activation domains have been studied intensively because they must interact with the general transcription machinery and therefore must play a critical regulatory role (for review, see Ptashne 1988; Mitchell and Tjian 1989; Lewin 1990; Ptashne and Gann 1990). The DNA-binding domain, however, is generally thought to simply direct the factor to the appropriate promoter and tether it to the DNA to allow the activation domain to manifest its activity. It is clear from the binding titration experiments described here that HSF and GAL4, both inducible transcription factors, differ dramatically with respect to how their binding ability is affected by nucleosomes. Certainly then, these DNAbinding domains are more than merely targeting surfaces and thus should not only be categorized by structural characteristics (e.g., helix-loop-helix, leucine zipper-basic region), but by functional activity as well (i.e., ability to bind to nucleosomal templates). The ability, or lack thereof, to bind to nucleosomal templates can have a dramatic effect on the mechanism by which such factors stimulate transcription. It seems likely that, analogous to activation domain function, the DNA-binding domains of transcription factors will prove to have an important regulatory activity in determining the ability of a factor to function in cellular chromatin.

\section{Materials and methods}

\section{Template construction}

Plasmids were constructed by using standard techniques. Plasmids $\mathrm{pG}_{1}$ hsp70-CAT (chloramphenicol acetyltransferase), $\mathrm{pG}_{2}$ hsp 70-CAT, and $\mathrm{pG}_{5}$ hsp70-CAT contain one, two, and five GAL4-binding sites, respectively, located $18 \mathrm{bp}$ upstream of the human $h s p 70 A$ TATA box. Plasmid pSH34-CAT contains the extended HSE fragment 17 bp upstream of the $h s p 70 A$ TATA site.

Templates containing one and five GAL4-binding sites $23 \mathrm{bp}$ from the artificial nucleosome-positioning sequence $/ G T$, Shrader and Crothers 1989/ were named pGT/GALl and pGT/ GAL5, respectively. The construct placing the extended HSE 28 bp from the positioning sequence was named pGT/EHSE. Templates that inserted $4 \mathrm{bp}$ between the single GAL4 site or extended HSE and the positioning sequence were created by restricting the parent plasmids pGT/GAL1 and pGT/EHSE at $X b a I$, end-filling with Klenow, and ligating. These plasmids were named $\mathrm{pGT} / \mathrm{GAL} 1+4$ and $\mathrm{pGT} / \mathrm{EHSE}+4$. To delete base pairs between these binding elements and the positioning sequence, the parent plasmids were restricted at $X b a \mathrm{I}$ and digested with mung bean nuclease before ligation. The resulting plasmids were named pGT/GAL1-5, pGT/GAL1-10, pGT/EHSE-4, and $\mathrm{pGT} / \mathrm{EHSE}-12$.

\section{Description of probes used in nucleosome assembly-binding} reactions

All fragments were isolated from low-melting-temperature agarose (SeaPlaque, FMC Bioproducts), and 5 -end-labeled with Klenow.

For Figure 1, A and B, a 170-bp fragment containing five GAL4 sites was created from $\mathrm{pG}_{5} \mathrm{hsp} 70-\mathrm{CAT}$. This probe contains five copies of the sequence 5'-CGGAGGACAGTACTCCG-3' (Carey et al. 1989), starting 22 bases from one end.

For Figure 2A, a 195-bp fragment containing bases -188 to +7 of the human $h s p 70 A$ promoter was created from plasmid $\mathrm{p} \Delta \mathrm{H}-18$ (Greene et al. 1987). This fragment contains an HSE with $3 n$ GAAn repeats centered at -100 . The sequence of the HSE is 5'-GGAATATTCCCGAC-3'.

For Figures $2 B$ and $4 A$, a 155-bp fragment with the extended HSE centered was isolated from $\mathrm{pGT} / \mathrm{EHSE}$. The same procedure was followed with plasmids pGT/EHSE $+4,-4$, and -12 (Fig. 4B), and for the appropriate pGT/GAL1 construct (Fig. 5A and data not shown). The sequence of the extended HSE is 5'-GGAGTCGAAACTTCTGGAATATTCCCGAACTTTC-3' (Greene and Kingston 1990), and the sequence of the artificial nucleosome-positioning sequence $(\mathrm{GT})$ is $5^{\prime}$-CTCGGTTTAGAGCCTGTAAC- ${ }^{\prime}$ (Shrader and Crothers 1989).

The 3000-bp linear probes were isolated from $\mathrm{pG}_{1}$ hsp70-CAT and $\mathrm{pG}_{5}$ hsp70-CAT (Fig. 3). In Figure 6, pSH34-CAT and pSHSE/T (extended HSE/TATA mutant; Greene and Kingston 1990) were the parent plasmids for these probes.

\section{Preparation of protein fractions}

Xenopus heat-treated egg supernatants containing nucleosome assembly factors were prepared according to Laskey et al. (1978). HeLa core histones ( $\mathrm{H} 2 \mathrm{~A}, \mathrm{H} 2 \mathrm{~B}, \mathrm{H} 3$, and $\mathrm{H} 4)$ were purified according to Stein and Mitchell (1988). Frog erythrocyte histones (core histones plus $\mathrm{H} 5$ and $\mathrm{H} 1$ ) were prepared as described previously (Workman et al. 1988). HSF was purified to homogeneity from HeLa cells with two affinity column passes (Schuetz et al. 1991). The GAL4 derivatives and byTFIID were purified from expressing bacterial strains (Workman et al. 1991). The concentration of these proteins was determined by the Bradford assay. HSF concentration was $0.1 \mathrm{mg} / \mathrm{ml}$. The concentration of the byTFIID was also $0.1 \mathrm{mg} / \mathrm{ml}$, but this preparation was $\sim 25 \%$ pure as judged from a silver-stained SDS-PAGE gel, leaving the effective concentration at $25 \mu \mathrm{g} / \mathrm{ml}$. The effective concentration of the GAL4-AH preparation, which was judged to be $95 \%$ pure, was $1.3 \mathrm{mg} / \mathrm{ml}$. The effective concentrations of GAL4(194) and GAL4-VP16 (both judged $\sim 60 \%$ pure) were 0.8 and 0.29 $\mathrm{mg} / \mathrm{ml}$, respectively.

\section{General nucleosome assembly-binding reaction conditions}

Nucleosome assembly mixtures $(10 \mu l)$ consisted of heattreated egg supernatant $(8 \mu \mathrm{l} ; 0.4 \mathrm{mg} / \mathrm{ml})$ and $2 \mu \mathrm{l}$ of a histone dilution [dilutions were in TE $(10 \mathrm{~mm}$ Tris $(\mathrm{pH} 8.0), 1 \mathrm{~mm}$ EDTA)] containing either $200 \mathrm{ng}$ of HeLa core histones or $500 \mathrm{ng}$ of frog erythrocyte histones (see figure legends). This mixture was incubated for $15 \mathrm{~min}$ at $20^{\circ} \mathrm{C}$ to allow the histones to bind assembly factors. Ten microliters of this mixture was added to an assembly reaction (final volume, $24 \mu$ l) giving final conditions of $7 \mathrm{~mm}$ HEPES $(\mathrm{pH} 7.9), 4 \mathrm{~mm}$ Tris-HCl $(\mathrm{pH} 8.0), 7 \%$ glycerol, $60 \mathrm{mM} \mathrm{KCl}, 70 \mu \mathrm{M}$ EDTA, $3.6 \mathrm{~mm}$ 2-mercaptoethanol, $1 \mathrm{mM} \mathrm{MgCl}, 100 \mathrm{ng}$ carrier DNA (pUC-18 or nonspecific plasmid), and $0.05-4 \mathrm{ng}$ of $5^{\prime}$-end-labeled fragment (see above). Nucleosome-assembly reactions were incubated at $30^{\circ} \mathrm{C}$ for $1 \mathrm{hr}$. Subsequent to assembly, $1 \mu$ l of purified HSF or GAL4 derivatives (at the amounts indicated in the figure legends) was added. The reactions were incubated for an additional $30 \mathrm{~min}$ at $30^{\circ} \mathrm{C}$, and binding was assayed by mobility shift or DNase I footprinting (see below). Dilutions of HSF were done in $20 \mathrm{~mm}$ HEPES (pH 7.9), 20\% glycerol, $100 \mathrm{~mm} \mathrm{KCl}, 0.2 \mathrm{~mm}$ EDTA, $0.5 \mathrm{~mm}$ DTT, $0.5 \mathrm{~mm}$ PMSF, $0.5 \mathrm{~mm}$ benzamidine, $1 \mu \mathrm{g} / \mathrm{ml}$ each of leupeptin, aprotinin, and pepstatin A; $0.1 \%$ NP-40, $5 \mathrm{~mm} \mathrm{n}$ octylglucoside, and $0.1 \mathrm{mg} / \mathrm{ml}$ hemoglobin. Dilutions of the 
GAL4 derivatives were performed in $20 \mathrm{~mm}$ HEPES ( $\mathrm{pH} 7.9$ ) $20 \%$ glycerol, $100 \mathrm{~mm} \mathrm{KCl}, 0.2 \mathrm{~mm}$ EDTA, $10 \mathrm{~mm} 2$-mercaptoethanol, $10 \mathrm{mM} \mathrm{ZnCl}_{2}$, and $1 \mathrm{mg} / \mathrm{ml}$ of BSA. When the proteins were omitted, $1 \mu$ l of the appropriate dilution buffer was added instead.

\section{Nucleosome assembly by salt dialysis histone transfer}

Nucleosome core particles were prepared from HeLa cell Hldepleted chromatin essentially as described in Kornberg et al. (1989). Twenty nanograms of labeled fragment was mixed with an amount of nucleosome cores containing $165 \mu \mathrm{g}$ of DNA in $100 \mu \mathrm{l}$ and dialyzed against $200 \mathrm{ml}$ of $2 \mathrm{M} \mathrm{NaCl}, 10 \mathrm{mM}$ Tris- $\mathrm{HCl}$ (pH 7.5), $1 \mathrm{~mm}$ EDTA, and $0.5 \mathrm{~mm}$ PMSF for $4 \mathrm{hr}$ at $4^{\circ} \mathrm{C}$. Six hundred milliliters of $10 \mathrm{~mm}$ Tris- $\mathrm{HCl}(\mathrm{pH} 7.5), 1 \mathrm{~mm}$ EDTA, and $0.5 \mathrm{mM}$ PMSF were then added at a rate of $40 \mathrm{ml} / \mathrm{hr}$ with a peristaltic pump over $15 \mathrm{hr}$. After an additional $2 \mathrm{hr}$ of dialysis the samples were dialyzed against $0.1 \mathrm{M} \mathrm{NaCl}, 10 \mathrm{mM}$ Tris- $\mathrm{HCl}$ (pH 7.5), $1 \mathrm{~mm}$ EDTA, and 0.5 mM PMSF for $4 \mathrm{hr}$. The reconstituted samples were centrifuged for $5 \mathrm{~min}$ in a microcentrifuge, and the supernatants were loaded on $5.4-\mathrm{ml} 5-20 \%$ sucrose gradients containing $100 \mathrm{mM} \mathrm{KCl}, 10 \mathrm{~mm}$ HEPES (pH 7.5), $1 \mathrm{mM}$ EDTA, and $100 \mu \mathrm{m} / \mathrm{ml} \mathrm{BSA}$. After centrifugation at $29,000 \mathrm{rpm}, 4^{\circ} \mathrm{C}$ for $20 \mathrm{hr}$ in an SW55 rotor, $0.2-\mathrm{ml}$ fractions were collected from the gradients and counted, and the $11 \mathrm{~S}$ nucleosome core peak fractions were pooled. In the experiment shown in Figure 2B, $5 \mu$ l of the pooled fractions was used per reaction corresponding to $0.13 \mathrm{ng}$ of HSE-containing probe fragment and $1.1 \mu \mathrm{g}$ of nucleosome core DNA as reconstituted nucleosome core particles. For the naked DNA controls, the gradient-purified core particles were extracted with phenol, followed by chloroform, ethanol-precipitated, and resuspended in the original volume of gradient buffers such that the DNA and sucrose concentrations were equivalent to that in the purifiedcore particle preparations.

\section{Nucleosome-binding assays}

Mobility-shift analysis Nucleosome assembly-binding reactions were resolved on $4 \%$ acrylamide $(40: 1)$ gels in $0.5 \times \mathrm{TBE}$ (45 mM Tris base, $45 \mathrm{~mm}$ boric acid, $1.25 \mathrm{~mm}$ EDTA). The running buffer was $0.5 \times$ TBE.

DNase I footprinting Subsequent to the nucleosome assembly-binding reactions, $4 \mu \mathrm{l}$ of a mixture consisting of $2 \mu \mathrm{l}$ of 40 $\mathrm{mM} \mathrm{CaCl}_{2}$ (final concentration, $2.7 \mathrm{mM}$ ) and $2 \mu \mathrm{l}$ of an RQ1 DNase I (Promega) dilution were added. Reactions lacking histones were digested with 0.2 units of DNase, whereas the assembled templates were digested with 2 units. Digestion times varied: Reactions with the 3000 -bp templates were digested for $1 \mathrm{~min}$ at room temperature, whereas templates that contained artificial nucleosome-positioning sequences were digested for 2 min at room temperature. The reactions were quenched with 2 $\mu l$ of $0.5 \mathrm{M}$ EDTA, extracted once with phenol/chloroform/ isoamyl alcohol, and ethanol-precipitated. The samples were dissolved in formamide with dyes and run on $0.4-\mathrm{mm}$-thick $5 \%$ (for 3000 -bp templates) or $10 \%$ (for shorter templates) acrylamide $/ 8 \mathrm{M}$ urea sequencing gels. The wet gel was exposed to XAR film (Kodak) at $-80^{\circ} \mathrm{C}$.

\section{Dissociation constant calculations}

Mobility-shift titration experiments were quantitated to determine the percentage of HSF and GAL4 molecules in our purified preparations that were active for binding. The HSF preparation at $100 \mathrm{ng} / \mathrm{\mu l}$ was determined to be $95 \%$ active for binding, whereas the GAL4-AH preparation at $1.33 \mu \mathrm{g} / \mu \mathrm{l}$ was $90 \%$ active for binding. HSF and GAL4-AH have molecular masses of $87 \mathrm{kD}$ and $20 \mathrm{kD}$, respectively. Binding titrations assayed by DNase I footprinting were performed with both 3000- and 150bp templates $(0.5$ fmole probe per $25 \mu \mathrm{l}$ reaction). The amounts of protein required for a half-maximal footprint was determined by quantitating the footprint gels on a Betascope 603 blot analyzer (Betagen). Ninety-five picograms, or .1 fmole, of HSF was calculated to be required for a half-maximal footprint. This yields a $K_{\mathrm{d}}$ of $\sim 4 \times 10^{-11} \mathrm{M}$. Note that this dissociation constant is close to the template concentration $\left(2 \times 10^{-11} \mathrm{M}\right)$, so we cannot rigorously demonstrate that we are limiting for template in these experiments with HSF. Therefore, the $4 \times 10^{-11} \mathrm{M}$ value should be taken as an upper limit on the dissociation constant for HSF. For GAL4-AH, a half-maximal footprint was calculated at $0.6 \mathrm{ng}$, or 30 fmoles. Thus, the $K_{\mathrm{d}}$ for GAL4-AH is $\sim 1.2 \times 10^{-9} \mathrm{M}$. Similar values were calculated for GAL4(1-94) and GAL4-VPI6 (data not shown).

\section{Acknowledgments}

We thank T. Shrader and D. Crothers for providing the artificial nucleosome-positioning sequence constructs and Andrea McClatchey for help in preparing the HeLa core histones. We are grateful to S. Liang and M. Ptashne for communicating unpublished results and A. Wolffe for useful suggestions. We thank R. Feinbaum, F. Ausubel, D. Moore, M. Mindrinos, and L. Sheldon for useful comments on the manuscript. This work was supported by a grant from Hoechst AG. J.L.W. is a Special Fellow of the Leukemia Society of America, Inc.

The publication costs of this article were defrayed in part by payment of page charges. This article must therefore be hereby marked "advertisement" in accordance with 18 USC section 1734 solely to indicate this fact.

\section{References}

Abravaya, K. B. Phillips, and R.I. Morimoto. 1991. Heat shockinduced interactions of heat shock transcription factor and the human hsp70 promoter examined by in vivo footprinting. Mol. Cell. Biol. 11: 586-592.

Almer, A. and W. Horz. 1986. Nuclease hypersensitive regions with adjacent positioned nucleosomes mark the gene boundaries of the PHO5/PHO3 locus in yeast. EMBO I. 5: 26812687.

Almer, A., H. Rudolph, A. Hinnen, and W. Horz. 1986. Removal of positioned nucleosomes from the yeast PHO5 promoter upon PHO5 induction releases additional upstream activating DNA elements. EMBO J. 5: 2689-2696.

Amin, J., J. Ananthan, and R. Voellmy. 1988. Key features of heat shock regulatory elements. Mol. Cell. Biol. 8: 37613769.

Archer, T.K., M.G. Cordingley, R.G. Wolford, and G.L. Hager. 1991. Transcription factor access is mediated by accurately positioned nucleosomes on the mouse mammary tumor virus promoter. Mol. Cell. Biol. 11: 688-698.

Bienz, M. and H.R.B. Pelham. 1986. Heat shock regulatory elements function as an inducible enhancer in the Xenopus hsp70 gene and when linked to a heterologous promoter. Cell 45: 753-760.

Brenowitz, M., D.F. Senear, M.A. Shea, and G.K. Ackers. 1986. Footprint titrations yield valid thermodynamic isotherms. Proc. Natl. Acad. Sci. 83: 8462-8466.

Brown, D.D. 1984. The role of stable complexes that repress and activate eucaryotic genes. Cell 37: 359-365. 
Brown, M.E., J. Amiin, P. Schiller, R. Voellmy, and W.A. Scott. 1988. Determinants for the DNase I hypersensitive chromatin structure $5^{\prime}$ to a human HSP70 gene. /. Mol. Biol. 203: $107-117$.

Carey, M., H. Kakidani, J. Leatherwood, F. Mostashari, and M. Ptashne. 1989. An amino-terminal fragment of GAL4 binds DNA as a dimer. J. Mol. Biol. 209: 423-432.

Carey, M., J. Leatherwood, and M. Ptashne. 1990a. A potent GAL4 derivative activates transcription at a distance in vitro. Science 247: 710-712.

Carey, M., Y.-S. Lin, M.R. Green, and M. Ptashne. 1990b. A mechanism for synergistic activation of a mammalian gene by GAL4 derivatives. Nature 345: 361-364.

Chasman, D.I., N.F. Lue, A.R. Buchman, J.W. LaPointe, Y. Lorch, and R.D. Kornberg. 1990. A yeast protein that influences the chromatin structure of $\mathrm{UAS}_{\mathrm{G}}$ and functions as a powerful auxiliary gene activator. Genes \& Dev. 4: 503-514.

Clark-Adams, C.D., D. Norris, M.A. Osley, J.S. Fassler, and F. Winston. 1988. Changes in histone gene dosage alter transcription in yeast. Genes \& Dev. 2: 150-159.

Cordingley, M.G., A.T. Riegel, and G.L. Hager. 1987. Steroiddependent interaction of transcription factors with the inducible promoter of mouse mammary tumor virus in vivo. Cell 48: 261-270.

Costlow, N.A., J.A. Simon, and J.T. Lis. 1985. A hypersensitive site in hsp 70 chromatin requires adjacent not internal DNA sequence. Nature 313: 147-149.

Elgin, S.C.R. 1988. The formation and function of DNase I hypersensitive sites in the process of gene activation. J. Biol. Chem. 263: 19259-19262.

- 1990. Chromatin structure and gene activity. Curr. Opin. Cell Biol. 2: 447-455.

Fedor, M.J., N.F. Lue, and R.D. Kornberg. 1988. Statistical positioning of nucleosomes by specific protein-binding to an upstream activating sequence in yeast. $J$. Mol. Biol. 204: 109-127.

Fedor, M.J. and R.D. Kornberg. 1989. Upstream sequence-dependent alteration of chromatin structure and transcriptional activation of the yeast GALl-GAL10 genes. Mol. Cell. Biol. 9: 1721-1732.

Gilmour, D.S. and J.T. Lis. 1986. RNA polymerase II interacts with the promoter region of the noninduced HSP70 gene in Drosophila melanogaster cells. Mol. Cell. Biol. 6: 3984 3989.

Giniger, E., S.M. Varnum, and M. Ptashne. 1985. Specific DNA binding of GAL4, a positive regulatory protein of yeast. Cell 40: 767-774.

Giniger, E. and M. Ptashne. 1987. Transcription in yeast activated by a putative amphipathic alpha helix linked to a DNA binding unit. Nature 330: 670-672.

Greene, J.M., Z. Larin, I.C.A. Taylor, H. Prentice, K.A. Gwinn, and R.E. Kingston. 1987. Multiple basal elements of a human hsp70 promoter function differently in human and rodent cell lines. Mol. Cell. Biol. 7: 3646-3655.

Greene, J.M. and R.E. Kingston. 1990. TATA-dependent and TATA-independent function of the basal and heat shock elements of a human hsp70 promoter. Mol. Cell. Biol. 10: $1319-1328$.

Gross, D.S. and W.T. Garrard. 1988. Nuclease hypersensitive sites in chromatin. Annu. Rev. Biochem. 57: 159-197.

Hahn, S., S. Buratowski, P.A. Sharp, and L. Guarente. 1990. Yeast TATA-binding protein TFIID binds to TATA elements with both consensus and nonconsensus DNA sequences. Proc. Natl. Acad. Sci. 86: 5718-5722.

Han, M. and M. Grunstein. 1988. Nucleosome loss activates downstream promoters in vivo. Cell 55: 1137-1145.
Hopper, J., I. Broach, and L. Rowe. 1978. Regulation of the galactose pathway in Saccharomyces cerevisiae: Induction of the uridyl transferase mRNA and dependency on GAL4 gene function. Proc. Natl. Acad. Sci. 75: 2878-2882.

Horikoshi, M., M.F. Carey, H. Kakidani, and R.G. Roeder. 1988. Mechanism of action of a yeast activator: Direct effect of GAL4 derivatives on mammalian TFIID-promoter interactions. Cell 54: 665-669.

Johnson, A.D., B.J. Meyer, and M. Ptashne. 1979. Interactions between DNA-bound repressors govern regulation by the lambda phage repressor. Proc. Natl. Acad. Sci. 76: 50615065.

Keene, M.A., V. Corces, K. Lowenhaupt, and S.C.R. Elgin. 1981. DNase I hypersensitive sites in Drosophila chromatin occur at the $5^{\prime}$ ends of regions of transcription. Proc. Natl. Acad. Sci. 78: 143-146.

Knezetic, J.A. and D.S. Luse. 1986. The presence of nucleosomes on a DNA template prevents initiation by RNA polymerase II in vitro. Cell 45: 95-104.

Kornberg, R.D., J.W. LaPointe, and Y. Lorch. 1989. Preparation of nucleosomes and chromatin. Methods Enzymol. 170: 314.

Kuwabara, M.D. and D.S. Sigman. 1987. Footprinting DNAprotein complexes in situ following gel retardation assays using 1,10-phenanthroline-copper ion: Escherichia coli RNA polymerase-lac promoter complexes. Biochemistry 26: 7234-7238.

Laskey, R.A., B.M. Honda, A.D. Mills, and J.T. Finch. 1978. Nucleosomes are assembled by an acidic protein which binds histones and transfers them to DNA. Nature 275: 416-420.

Lewin, B. 1990. Commitment and activation at Pol II promoters: A tail of protein-protein interactions. Cell 61: 11611164.

Lohr, D. and J.E. Hopper. 1985. The relationship of regulatory proteins and DNase I hypersensitive sites in the yeast GAL1GAL10 genes. Nucleic Acids Res. 13: 8409-8423.

Lorch, Y., J.W. LaPointe, and R.D. Kornberg. 1987. Nucleosomes inhibit the initiation of transcription but allow chain elongation with the displacement of histones. Cell 49: 203210

Mitchell, P.J. and R. Tjian. 1989. Transcriptional regulation in mammalian cells by sequence-specific DNA binding proteins. Science 245: 371-378.

Ondek, B., L. Gloss, and W. Herr. 1988. The SV40 enhancer contains two distinct levels of organization. Nature 333: 4045.

Perlmann, T. and O. Wrange. 1988. Specific glucocorticoid receptor binding to DNA reconstituted in a nucleosome EMBO /. 7: 3073-3079.

Pina, B., U. Bruggemeier, and M. Beato. 1990. Nucleosome positioning modulates accessibility of regulatory proteins to the mouse mammary tumor virus promoter. Cell 60: 719731

Ptashne, M. 1988. How eukaryotic transcriptional activators work. Nature 335: 683-689.

Ptashne, M. and A.A.F. Gann. 1990. Activators and targets. $\mathrm{Na-}$ ture 346: 329-331.

Rhodes, D. and R.A. Laskey. 1989. Assembly of nucleosomes and chromatin in vitro. Methods Enzymol. 170: 575-585.

Richard-Foy, H. and G.L. Hager. 1987. Sequence-specific positioning of nucleosomes over the steroid-inducible MMTV promoter. $E M B O$ I. 6: 2321-2328.

Sadowski, I., J. Ma, S. Triezenberg, and M. Ptashne. 1988. GAL4-VP16 is an unusually potent transcriptional activator. Nature 334: 563-564. 
Taylor et al.

St. John, T. and R. Davis. 1981. The organization and transcription of the galactose gene cluster of Saccharomyces. J. Mol. Biol. 152: 285-315.

Schuetz, T.J., G.J. Gallo, L. Sheldon, P. Tempst, and R.E. Kingston. 1991. Isolation of a cDNA for HSF2: Evidence for two heat shock factor genes in humans. Proc. Natl. Acad. Sci. (in press).

Selleck, S.B. and J.E. Majors. 1987. In vivo DNA-binding properties of a yeast transcription activator protein. Mol. Cell. Biol. 7: 3260-3267.

Shrader, T.E. and D.M. Crothers. 1989. Artificial nucleosome positioning sequences. Proc. Natl. Acad. Sci. 86: 7418-7422.

Singer, V.L., C.R. Wobbe, and K. Struhl. 1990. A wide variety of DNA sequences can functionally replace a yeast TATA element for transcriptional activation. Genes \& Dev. 4: 636645.

Stein, A. and M. Mitchell. 1988. Generation of different nucleosome spacing periodicities in vitro: Possible origins of cell type specificity. I. Mol. Biol. 203: 1029-1043.

Svaren, J. and R. Chalkley. 1990. The structure and assembly of active chromatin. Trends Genet. 6: 52-56.

Thomas, G.H. and S.C.R. Elgin. 1988. Protein/DNA architecture of the DNase I hypersensitive region of the Drosophila HSP26 promoter. EMBO I. 7: 2191-2201.

Webster, N., J.R. Jin, S. Green, M. Hollis, and P. Chambon. 1988. The yeast $\mathrm{UAS}_{\mathrm{G}}$ is a transcriptional enhancer in human HeLa cells in the presence of the GAL4 trans-activator. Cell 52: 169-178.

West, R.W. Jr., R.R. Yocum, and M. Ptashne. 1984. Saccharomyces cerevisiae GAL1-GAL10 divergent promoter region: Location and function of the upstream activating sequence $\mathrm{UAS}_{\mathrm{G}}$. Mol. Cell. Biol. 4: 2467-2478.

Wolffe, A.P. 1990. New approaches to chromatin function. New Biologist 2: 211-218.

Wolffe, A.P. and D.D. Brown. 1988. Developmental regulation of two 5S ribosomal RNA genes. Science 241: 1626-1632.

Workman, I.L., S.M. Abmayr, W.A. Cromlish, and R.G. Roeder. 1988. Transcriptional regulation by the immediate early protein of pseudorabies virus during in vitro nucleosome assembly. Cell 55: 211-219.

Workman, J.L., R.G. Roeder, and R.E. Kingston. 1990. An upstream transcription factor, USF (MLTF), facilitates the formation of preinitiation complexes during in vitro chromatin assembly. EMBO I. 9: 1299-1308.

Workman, J.L., I.C.A. Taylor, and R.E. Kingston. 1991. Activation domains of stably bound GAL4 derivatives alleviate repression of promoters by nucleosomes. Cell 64: 533-544.

Wu, C. 1980 . The $5^{\prime}$ ends of Drosophila heat shock genes in chromatin are hypersensitive to DNase I. Nature 286: 854 860.

-1984. Two protein-binding sites in chromatin implicated in the activation of heat shock genes. Nature 309: 229234.

Wu, B.J., G.T. Williams, and R.I. Morimoto. 1987. Detection of three protein binding sites in the serum-regulated promoter of the human gene encoding the $70 \mathrm{kDa}$ heat shock protein. Proc. Natl. Acad. Sci. 84: 2203-2207.

Xiao, H. and J. Lis. 1988. Germline transformation used to define key features of heat shock response elements. Science 238: $1247-1142$. 


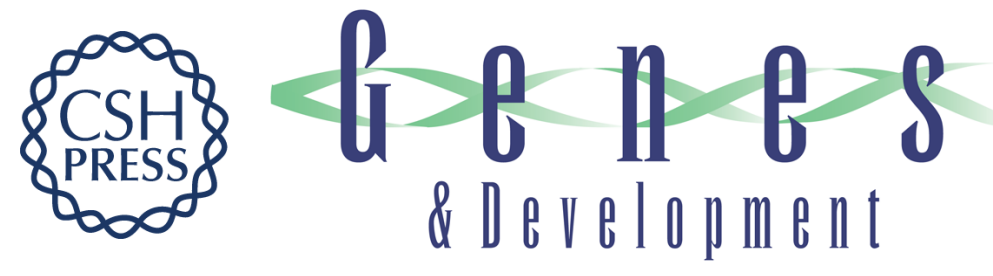

\section{Facilitated binding of GAL4 and heat shock factor to nucleosomal templates: differential function of DNA-binding domains.}

I C Taylor, J L Workman, T J Schuetz, et al.

Genes Dev. 1991, 5:

Access the most recent version at doi:10.1101/gad.5.7.1285

References This article cites 65 articles, 22 of which can be accessed free at: http://genesdev.cshlp.org/content/5/7/1285.full.html\#ref-list-1

License

Email Alerting

Service

Receive free email alerts when new articles cite this article - sign up in the box at the top right corner of the article or click here.

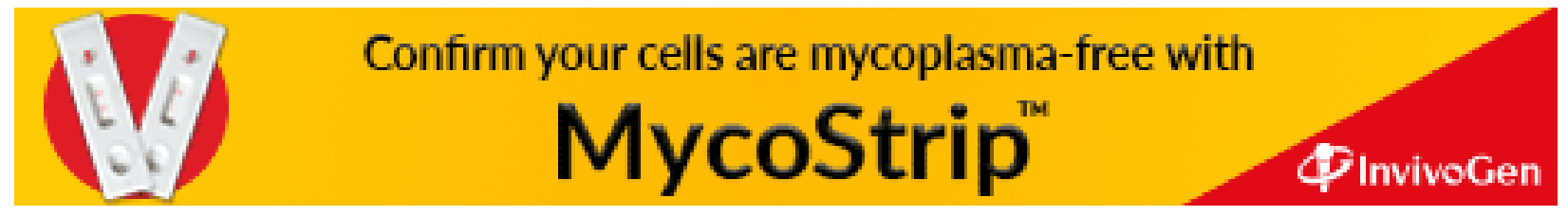

